\title{
Association between inaccurate estimation of body size and obesity in schoolchildren
}

\author{
Associação entre a inacurácia na estimação do tamanho corporal \\ e a obesidade em escolares
}

Larissa da Cunha Feio Costa, ${ }^{1}$ Diego Augusto Santos Silva, ${ }^{2}$ Sebastião de Sousa Almeida, ${ }^{3}$

Francisco de Assis Guedes de Vasconcelos ${ }^{1}$

\begin{abstract}
Objectives: To investigate the prevalence of inaccurate estimation of own body size among Brazilian schoolchildren of both sexes aged 7-10 years, and to test whether overweight/obesity; excess body fat and central obesity are associated with inaccuracy.

Methods: Accuracy of body size estimation was assessed using the Figure Rating Scale for Brazilian Children. Multinomial logistic regression was used to analyze associations.

Results: The overall prevalence of inaccurate body size estimation was $76 \%$, with $34 \%$ of the children underestimating their body size and $42 \%$ overestimating their body size. Obesity measured by body mass index was associated with underestimation of body size in both sexes, while central obesity was only associated with overestimation of body size among girls.

Conclusions: The results of this study suggest there is a high prevalence of inaccurate body size estimation and that inaccurate estimation is associated with obesity. Accurate estimation of own body size is important among obese schoolchildren because it may be the first step towards adopting healthy lifestyle behaviors.
\end{abstract}

Keywords: Body image, obesity, child, perception, cross-sectional studies.

\section{Resumo}

Objetivos: Investigar a prevalência de inacurácia na estimação do tamanho corporal em escolares brasileiros de ambos os sexos com idade entre 7 e 10 anos e testar a associação com o sobrepeso/obesidade, excesso de gordura corporal e obesidade central.

Métodos: A acurácia na estimação do tamanho corporal foi avaliada por meio da Escala de Silhuetas Brasileiras para crianças. As análises de associação foram realizadas por meio de regressão logística multinomial.

Resultados: A prevalência geral de inacurácia na estimação do tamanho corporal foi de $76 \%$, sendo que $34 \%$ das crianças subestimaram seu tamanho corporal e $42 \%$ o superestimaram. A obesidade medida por meio do índice de massa corporal foi associada a subestimação do tamanho corporal em ambos os sexos, enquanto que obesidade central se associou com superestimação do tamanho corporal apenas em meninas.

Conclusões: Os resultados deste estudo demonstram uma elevada prevalência de inacurácia na estimação do tamanho corporal e sua associação com a obesidade. A acurácia na estimação do tamanho corporal é importante entre escolares obesos, pois pode ser o primeiro passo para a adoção de comportamentos mais saudáveis de vida.

Descritores: Imagem corporal, obesidade, criança, percepção, estudos transversais.

\footnotetext{
${ }^{1}$ Graduate Program in Nutrition, Universidade Federal de Santa Catarina (UFSC), Florianópolis, SC, Brazil. 2 Graduate Program in Physical Education, UFSC, Florianópolis, SC, Brazil. ${ }^{3}$ Graduate Program in Psychobiology, Universidade de São Paulo (USP), Ribeirão Preto, SP, Brazil.

This manuscript was based on the first author's doctoral dissertation, currently underway, entitled "Obesidade e imagem corporal em escolares de 7 a 10 anos de Florianópolis, SC: um estudo transversal" (Obesity and body image in schoolchildren aged 7 to 10 years in Florianopolis, SC: a cross-sectional study), which will be submitted to the Universidade Federal de Santa Catarina (UFSC), Florianópolis, SC, Brazil, in 2016.

Financial support: Conselho Nacional de Desenvolvimento Científico e Tecnológico (CNPq; protocol no. 402322/2005-3) and Coordenação de Aperfeiçoamento de Pessoal de Nível Superior (CAPES; scholarship awarded to first author).

Submitted Feb 09 2015, accepted for publication Jul 14 2015. No conflicts of interest declared concerning the publication of this article.

Suggested citation: Costa LC, Silva DA, Almeida SS, de Vasconcelos FA. Association between inaccurate estimation of body size and obesity in schoolchildren. Trends Psychiatry Psychother. 2015;37(4):220-226. http://dx.doi.org/10.1590/2237-6089-2015-0009
} 


\section{Introduction}

Body image is conceptualized as the image one has in one's mind of the size, shape and contours of the body, as well as one's feelings about these characteristics, ${ }^{1}$ and thus includes two components: attitudinal and perceptual. ${ }^{2}$

The attitudinal component refers to feelings, thoughts and actions related to the body. The perceptual component involves evaluating the accuracy of the estimation of body size. ${ }^{2}$ Perceptual distortion corresponds to inaccurate judgment of body size, ${ }^{3}$ which has been recognized as an important psychobiological and sociocultural factor and linked to attitudes to weight control and eating disorders. ${ }^{4-6}$

Although the perceptual component is essential to the understanding of body image, few studies have evaluated it. The national and international literature reveals growing research interest in body image over the past decade. However, investigations have been focused on children in secondary education, ${ }^{7-10}$ college students ${ }^{11-13}$ and females ${ }^{7,11,12,14-16}$ and have tended to only evaluate the attitudinal component of body image. . $^{8,9,11-13,15,17}$

The literature suggests that body image is already formed in childhood, ${ }^{18}$ and the perceptual component is clearly related to development of eating disorders, ${ }^{5}$ which have been increasing in incidence among the male population. ${ }^{19,20}$ Furthermore, it has been shown that people who are overweight or obese, as assessed by body mass index (BMI), are more likely to estimate body size erroneously. ${ }^{4,21,22}$

Only one previous study was identified that investigated the associations between inaccurate body size estimation and BMI, percentage body fat $(\% \mathrm{BF})$ and waist circumference (WC), ${ }^{22}$ and this study only evaluated schoolchildren aged 12-16 years. To the best of our knowledge, no studies have been conducted with younger schoolchildren, aged 7-10 years. It is therefore considered important to investigate the prevalence of inaccurate estimation of own body size among schoolchildren of both sexes aged 7-10 years, and to test whether it is associated with overweight/obesity; excess body fat; and/or central obesity.

\section{Materials and methods}

\section{Participants}

This was a cross-sectional school-based study, conducted in 2012/2013, as part of a research project funded by the Conselho Nacional de Desenvolvimento Científico e Tecnológico (CNPq; protocol no. 402322/2005-3), in Florianópolis, the state capital of Santa Catarina, southern Brazil, using data from 1,530 schoolchildren aged 7 to 10 years.

Considering the total number of schoolchildren available and the prevalence rates of different exposure and outcome variables and after adjustments for confounding factors, this study had a power of $80 \%$ to detect a statistically significant $(p<005)$ odds ratio (OR) of between 0.77 and 0.66 for protective factors, and of between 1.23 and 1.34 for risk factors.

A cluster sampling process was employed. Schools were allocated to 10 strata, according to the administrative regions of Florianópolis (Center, Continent, North, East and South) and type of school (public or private). In each stratum, schools were randomly selected for inclusion in the study. A total of 30 schools were selected, 9 municipal-run public schools, 10 state-run public schools and 11 private schools. The classes from each school to be evaluated were subsequently selected at random from lists of the schoolchildren available at each institution.

The study was approved by the Ethics Committee at the Universidade Federal de Santa Catarina (Decision number 120341/2012) and written consent forms were signed by the parents or guardians of all schoolchildren.

\section{Procedure}

Anthropometric measurements were taken by a team of investigators, duly trained by a physical education professional who was an ISAK certified trainer (International Society for the Advancement of Kinanthropometry) and considered the benchmark for the anthropometric measurements used in this study. The quality of anthropometric measurements was assessed by absolute and relative technical errors of measurement (TEM) and reliability coefficients (R), according to parameters established by Habitcht, ${ }^{23}$ and by Ulijaszek $\&$ Kerr. ${ }^{24}$

\section{Measurements}

The outcome variable of this study was inaccurate body size estimation. Data were obtained using the Figure Rating Scale for Brazilian Children, which was created and validated for the Brazilian population of 7 to 12 -year-old children by Kakeshita et al. ${ }^{25}$ The Figure Rating Scale for Brazilian Children consists of a set of 11 figures for each sex printed on individual cards measuring $12.5 \mathrm{~cm} \times 6.5 \mathrm{~cm}$, with numbers on the other side. Each silhouette corresponds to a real 
interval of BMI for classification of the subject and a mean BMI determined for the purposes of calculation. The first silhouette represents a child with a BMI of $12 \mathrm{~kg} / \mathrm{m}^{2}$, and the last a child with a BMI of $29 \mathrm{~kg} /$ $\mathrm{m}^{2}$. Each successive figure represents a constant increase in BMI of $1.7 \mathrm{~kg} / \mathrm{m}^{2}$ over the previous figure. The validity of this scale was demonstrated by its high correlation with real BMI. ${ }^{25}$ The interviewers asked the schoolchildren to select the figure that was most similar to their own body (perceived BMI). Inaccuracy of body size estimation was assessed by subtracting the real BMI (obtained by anthropometric measurements of weight and height) from the perceived BMI (perceived BMI - real BMI). If the result of this subtraction was zero, the student was considered to have an accurate perception of body size. A positive subtraction result was considered an overestimation of body size, and a negative result was considered an underestimation of body size.

The independent variables were the measures of obesity: overweight or obesity (according to BMI); excess body fat (according to \%BF); and central obesity (according to WC). Additionally, age and sex of the child, type of school and mother's education level were included in the analysis model as control variables.

Anthropometric measurements were taken following procedures recommended in the literature. ${ }^{26}$ Measurements of body mass were obtained using an electronic scale (Marte ${ }^{\circledR}$, São Paulo, Brazil), with a maximum capacity of $200 \mathrm{~kg}$ and sensitivity of 50 grams. A stadiometer was used to measure height (Alturexata ${ }^{\circledR}$, Belo Horizonte, Brazil) with the zero point at ground level and a $0.5 \mathrm{~cm}$ scale. WC was measured using an inelastic anthropometric tape with a $0.1 \mathrm{~cm}$ scale (Lange ${ }^{\circledR}$, Cambridge, USA). Skinfold thickness (ST) measurements were taken with calipers with a $1 \mathrm{~mm}$ scale (Lange ${ }^{\circledR}$, Cambridge, USA). Measurements were taken on the right side of the body each skinfold measurement was taken three times and the mean was recorded as the final measurement.

Overweight or obesity for age and sex was defined according to World Health Organization reference data, ${ }^{27}$ which classifies BMI as low for age (BMI $<z$ score -2 ); normal weight (BMI $\geq z$ score -2 and $<$ $z$ score +1 ); overweight (BMI $\geq z$ score +1 and $<z$ score +2 ) and obesity (BMI $\geq z$ score +2 ). However, for the purposes of analysis, BMI was categorized as follows: not overweight/obese (BMI < z score +1 ); overweight (BMI z score $\geq+1$ and $<z$ score +2 ); and obese (BMI $z$ score $\geq+2$ ).

Excess body fat was estimated in the schoolchildren using triceps and subscapular skinfolds. Predictive equations published by Lohman ${ }^{28}$ were used to estimate
\%BF from these skinfold measurements. Children whose results were moderately high, high or very high were classified as having excess body fat, i.e., those with \%BF above 20.1 for boys and above 25.1 for girls. ${ }^{29}$

Central obesity for sex and age was diagnosed using the classification proposed by Taylor. ${ }^{30}$ The following WC cutoffs were used for the boys: $62.9 \mathrm{~cm}$ at 7 years of age; $65.3 \mathrm{~cm}$ at 8 years of age; $67.7 \mathrm{~cm}$ at 9 years of age; and $70.1 \mathrm{~cm}$ at 10 years of age. The following cutoffs were adopted for the girls: $62 \mathrm{~cm}$ at 7 years of age; $64.7 \mathrm{~cm}$ at 8 years of age; $67.3 \mathrm{~cm}$ at 9 years of age; and $69.6 \mathrm{~cm}$ at 10 years of age.

\section{Statistical analyses}

A database was created with Epi Data version 3.2 and data were processed by a team of typists who had been trained in advance, using a double-entry system. Statistical analysis was performed using STATA version 11.0. Analyses were adjusted for the effects of the design and study sample using the SVY command.

Multinomial logistic regression was used to analyze associations. Initially, bivariate analysis was used to test for associations between the dependent variable (inaccurate body size estimation) and each independent variable (BMI, \%BF and WC), and each control variable (age, sex, school type and mother's education). Independent and control variables for which $\mathrm{p}$ was $<0.20$ were included and maintained in the adjusted analysis, yielding OR values and 95\% confidence intervals ( $95 \% \mathrm{CI})$. Analyses of associations were stratified by sex and the cutoff for significance was set at $5 \%(p<0.05)$.

\section{Results}

Sample characteristics and anthropometry and body image results are shown in Table 1 . The overall prevalence of inaccurate body size estimation was $76 \%$ of the sample, of which $34 \%$ of schoolchildren underestimated their body size and $42 \%$ overestimated their body size, with a similar distribution between the sexes.

The adjusted multinomial logistic regression model was controlled for the variables child's age and mother's educational level, since the bivariate analyses returned $p$-values of $<0.20$ for both sexes. The results of this analysis for the boys only showed that obesity evaluated by BMI remained independently associated with underestimation of body size. Obese boys (BMI) were 6.5 times more likely to underestimate their silhouettes when compared to children without overweight (Table 2). 
Table 1 - Characteristics of the sample and anthropometry and body image results $(n=1,530)$, for schoolchildren aged 7-10 years

\begin{tabular}{|c|c|c|c|}
\hline Variables & $\begin{array}{c}\text { Boys } \\
(n=725)\end{array}$ & $\begin{array}{c}\text { Girls } \\
(\mathrm{n}=\mathbf{8 0 5})\end{array}$ & $\begin{array}{c}\text { Total } \\
(n=1,530)\end{array}$ \\
\hline Age (years) & $8.47 \pm 1.1$ & $8.48 \pm 1.1$ & $8.48 \pm 1.1$ \\
\hline 7-8 years & $415(57.2)$ & $452(56.1)$ & $866(56.6)$ \\
\hline $9-10$ years & $310(42.8)$ & $353(43.9)$ & $664(43.4)$ \\
\hline \multicolumn{4}{|l|}{ Type of school } \\
\hline Public & $462(63.7)$ & $473(58.7)$ & $933(61.0)$ \\
\hline Private & $263(36.3)$ & $332(41.3)$ & $597(39.0)$ \\
\hline \multicolumn{4}{|l|}{ Mother's education } \\
\hline None/primary unfinished & $106(15.2)$ & $126(16.2)$ & $232(15.7)$ \\
\hline Graduated primary education & $110(15.8)$ & $108(14.0)$ & $218(14.8)$ \\
\hline Graduated secondary education & $255(36.6)$ & $315(40.4)$ & $572(38.7)$ \\
\hline Graduated higher education & $227(32.4)$ & $229(29.4)$ & $454(30.8)$ \\
\hline Real BMI $\left(\mathrm{kg} / \mathrm{m}^{2}\right)$ & $18.0 \pm 3.1$ & $17.6 \pm 3.1$ & $17.8 \pm 3.1$ \\
\hline Low weight & $5(0.7)$ & $3(0.4)$ & $8(0.6)$ \\
\hline Normal weight & $427(59.1)$ & $525(65.7)$ & $954(62.7)$ \\
\hline Overweight & $175(24.3)$ & $181(22.7)$ & $356(23.4)$ \\
\hline Obesity & $115(15.9)$ & $90(11.2)$ & $203(13.3)$ \\
\hline$\% \mathrm{BF}$ & $19.2 \pm 7.6$ & $23.1 \pm 6.7$ & $21.22 \pm 7.4$ \\
\hline No excess body fat & $439(60.8)$ & $507(63.6)$ & $947(62.3)$ \\
\hline Excess body fat & $283(39.2)$ & $290(36.4)$ & $572(37.7)$ \\
\hline Weight circumference $(\mathrm{cm})$ & $60.3 \pm 7.5$ & $58.4 \pm 7.3$ & $59.30 \pm 7.4$ \\
\hline No central obesity & $608(84.4)$ & $677(84.8)$ & $1,285(84.6)$ \\
\hline Central obesity & $112(15.6)$ & $121(15.2)$ & $233(15.4)$ \\
\hline Perceived BMI $\left(\mathrm{kg} / \mathrm{m}^{2}\right)$ & $18.3 \pm 3.3$ & $17.7 \pm 3.4$ & $17.8 \pm 3.1$ \\
\hline Body size estimation error* & $0.35 \pm 3.2$ & $0.13 \pm 3.0$ & $0.23 \pm 3.1$ \\
\hline Accurate & $149(21.2)$ & $208(26.2)$ & $359(24.0)$ \\
\hline Underestimated & $250(35.5)$ & $266(33.3)$ & $514(34.3)$ \\
\hline Overestimated & $304(43.3)$ & $322(40.5)$ & $626(41.7)$ \\
\hline
\end{tabular}

Data presented as mean \pm standard deviation or $\mathrm{n}(\%)$.

$\% \mathrm{BF}=$ percentage body fat; $\mathrm{BMI}=$ body mass index.

* Perceived BMI minus real BMI.

Table 2 - Multinomial logistic regression of inaccurate estimation of body image among male schoolchildren aged 7-10 years

\begin{tabular}{|c|c|c|c|c|c|c|}
\hline \multirow[b]{2}{*}{ Variables } & \multicolumn{3}{|c|}{ Underestimation } & \multicolumn{3}{|c|}{ Overestimation } \\
\hline & adjusted OR * & $95 \% \mathrm{CI}$ & p-value & adjusted OR * & $95 \% \mathrm{CI}$ & p-value \\
\hline Overweight/obesity (BMI) & & & 0.008 & & & 0.979 \\
\hline No overweight/obesity & 1 & & & 1 & & \\
\hline Overweight & 0.85 & $0.67-5.06$ & & 0.69 & $0.21-2.30$ & \\
\hline Obese & 6.47 & $1.95-21.49$ & & 1.50 & $0.32-7.04$ & \\
\hline Excess body fat (\%BF) & & & 0.888 & & & 0.752 \\
\hline No excess body fat & 1 & & & 1 & & \\
\hline Excess body fat & 1.05 & $0.51-2.16$ & & 0.87 & $0.34-2.19$ & \\
\hline Central obesity (WC) & & & 0.206 & & & 0.060 \\
\hline No central obesity & 1 & & & 1 & & \\
\hline Central obesity & 0.56 & $0.23-1.40$ & & 0.40 & $0.15-1.04$ & \\
\hline
\end{tabular}

$95 \% \mathrm{CI}=95 \%$ confidence interval; $\% \mathrm{BF}=$ percentage body fat; $\mathrm{BMI}=$ body mass index OR = odds ratio; WC = waist circumference.

* Adjusted for child's age and educational level of mother - independent variables for which $\mathrm{p}$ was $\leq 0.20$ in the bivariate analysis.

Bold indicates variables for which $\mathrm{p}$ was $\leq 0.05$.

Among girls, obesity evaluated by BMI remained associated with underestimation of body size, and central obesity determined by WC remained associated with overestimation of body size in the adjusted model. Girls who were obese according to their BMI were 4.0 times more likely to underestimate their silhouettes, compared to girls who were not overweight/obese, while girls with central obesity were 4.0 times more likely to overestimate their silhouettes (Table 3). 
Inaccurate estimation of body size - Costa et al.

Table 3 - Multinomial logistic regression of inaccurate estimation of body image among female schoolchildren aged 7-10 years

\begin{tabular}{|c|c|c|c|c|c|c|}
\hline \multirow[b]{2}{*}{ Variables } & \multicolumn{3}{|c|}{ Underestimation } & \multicolumn{3}{|c|}{ Overestimation } \\
\hline & adjusted OR * & $95 \% \mathrm{CI}$ & p-value & adjusted OR * & $95 \% \mathrm{CI}$ & p-value \\
\hline Overweight/obesity (BMI) & & & 0.021 & & & 0.510 \\
\hline No overweight/obesity & 1 & & & 1 & & \\
\hline Overweight & 1.89 & $0.92-3.90$ & & 0.62 & $0.30-1.29$ & \\
\hline Obese & 4.05 & $1.43-11.49$ & & 1.01 & $0.27-3.75$ & \\
\hline Excess body fat (\%BF) & & & 0.124 & & & 0.066 \\
\hline No excess body fat & 1 & & & 1 & & \\
\hline Excess body fat & 1.68 & $0.86-3.30$ & & 0.49 & $0.23-1.05$ & \\
\hline Central obesity (WC) & & & 0.414 & & & 0.018 \\
\hline No central obesity & 1 & & & 1 & & \\
\hline Central obesity & 1.53 & $0.54-4.35$ & & 3.98 & $1.30-12.21$ & \\
\hline
\end{tabular}

$95 \% \mathrm{CI}=95 \%$ confidence interval $\% \mathrm{BF}=$ percentage body fat; $\mathrm{BMI}=$ body mass index; OR = odds ratio; $\mathrm{WC}=$ waist circumference.

* Adjusted for child's age and educational level of mother - independent variables for which $p$ was $\leq 0.20$ in the bivariate analysis.

Bold indicates variables for which $p$ was $\leq 0.05$.

\section{Discussion}

The prevalence of inaccurate body size estimation among the schoolchildren surveyed was $76 \%$. There are currently no studies of the prevalence of inaccurate body image estimation in this age group (7-10 years) using the same evaluation tools used in this study. However, it appears that the prevalence of inaccuracy is high in comparison to studies that have surveyed schoolchildren of different age groups and using other assessment tools, in which reported prevalence rates range from $22.6 \%$ to $58.0 \% .4,22,31-34$

It is important to stress that the questionnaires used as evaluation instruments in these studies have not been validated for this use and so the discrepancies between prevalence results may be related to greater sensitivity of the instrument used in the present study. Notwithstanding these methodological differences, it is necessary to carry out studies to evaluate whether perception that is inaccurate by just one figure in the range of silhouettes should be considered tolerable or not, given that the increment between the figures on the Figure Rating Scale for Brazilian Children used is 1.7 $\mathrm{kg} / \mathrm{m}^{2}$, which may be considered a small variation. It is noteworthy that while $76 \%$ of schoolchildren estimated their own body size inaccurately, $38 \%$ erred by just one figure (data not shown in tables).

The present study revealed a greater chance of body underestimation among both boys and girls with obesity according to BMI, and a greater chance of body overestimation among girls with central obesity.

Excess body fat was not found to be associated with estimation of body size in either sex, which may be influenced by the fact that, unlike weight, height and WC, people cannot always assess it visually. ${ }^{22}$
Underestimation of own body size by obese subjects has also been observed in other studies. Maximova et al., ${ }^{21}$ conducted a study of 3,665 Canadian children aged 9, 13 and 16 years, and found that children with overweight and obesity were significantly more likely to underestimate their body size when compared to those without overweight/obesity. Russin et al. ${ }^{35}$ evaluated the perceptions of own body image of 106 children aged 8-12 years in the UK, and found that obese children had a marked tendency to underestimate their body size. Frederickson et al. ${ }^{22}$ also found that schoolchildren with overweight and obesity were more likely to underestimate their body size.

According to Castro et al. ${ }^{36}$ underestimation of body size by those with obesity may represent a rejection, albeit unconscious, of the person's real body for diverse reasons, one of which is a feeling of inadequacy compared to the standard body image.

The literature indicates that overweight or obese children and adolescents are more likely to become obese adults. ${ }^{37}$ It is important to reach this age group through activities that are designed to avert problems related to body satisfaction, sociability, diet and sedentary lifestyle. ${ }^{35}$ However, underestimation of body size in this group may limit commitment to programs for the promotion of healthy lifestyles. ${ }^{21}$

With regard to the association between body overestimation and WC in girls, these results differ from those of two other studies conducted with female schoolchildren. In a study conducted in Finland by Van Vliet et al., ${ }^{38}$ WC was associated with more accurate body estimation, whereas in a study conducted in Australia by Frederickson et al.,22 WC was associated with greater underestimation of body size. Some of these differences can be attributed to the different cutoff 
points for evaluation of WC used in the studies, but it is assumed that due to the fact that WC identifies the abdominal concentration of body fat, 39,40 the condition of obesity was more evident in girls, which may have led to overestimation of their body size. According to Smolak, ${ }^{41}$ socially established body standards can influence how individuals view their bodies and from preschool years onwards, girls especially begin to make social comparisons and to develop the belief that beauty is a positive stereotype and that attractiveness is valued socially, while they also begin to recognize that being overweight is not the starting point for being beautiful.

Girls who overestimate body size may be at risk of engaging in unnecessary or unhealthy weight control, because overestimation of body size is associated with dissatisfaction with body image and weight control behavior that could put health at risk, such as restrictive diets, laxatives and diuretics, or excessive exercise in adults. ${ }^{42,43}$

This is the first study to evaluate the prevalence of inaccurate body size estimation and its association with overweight/obesity; excess body fat; and central obesity in schoolchildren of both sexes aged 7-10 years. The methods adopted for calculations and sample selection, the methodological rigor and the standardization of anthropometric measurements in this study all contribute to the success in achieving results that have internal validity and which may also reflect the situation elsewhere in the country.

However, limitations of the study include the crosssectional sampling design adopted, which does not allow temporal relationship to be established between variables, and the use of anthropometric measurements to assess obesity.

The results of this study allow us to conclude that there is a high prevalence of inaccurate body size estimation among schoolchildren aged 7-10 years, and that this is associated with obesity (BMI) in both sexes and with central obesity among girls. These results also lead us to reflect on the importance of accuracy in estimation of body size among obese schoolchildren, since underestimation of body size may limit the schoolchildren's participation in interventions to control obesity and promote healthy living, ${ }^{44}$ while overestimation of body size can lead them to adopt restrictive eating habits and compensatory methods for weight control. ${ }^{43}$

\section{Acknowledgements}

The authors would like to thank the Conselho Nacional de Desenvolvimento Científico e Tecnológico (CNPq) for funding this project (protocol no. 402322/2005-3) and the Coordenação de Aperfeiçoamento de Pessoal de Nível Superior (CAPES) for providing financial support in the form of a scholarship awarded to the lead author.

\section{References}

1. Slade PD. What is body image? Behav Res Ther. 1994;32:497-502.

2. Cash TF, Wood KC, Phelps KD, Boyd K. New assessments of weight-related body image derived from extant instruments. Percept Mot Skills. 1991;73:235-41.

3. Gardner RM. Body image assessment of children. In: Cash TF, Pruzinsky T. Body image: a handbook of theory, research, and clinical practice. New York: Guilford; 2002. p. 127.

4. O'Dea JA, Caputi P. Association between socioeconomic status, weight, age and gender, and the body image and weight control practices of 6 -to 19 -year-old children and adolescents. Health Educ Res. 2001;16:521-32.

5. Thompson JK, Gardner RM. Measuring perceptual body image among adolescents and adults. In: Cash TF, Pruzinsky T. Body image: a handbook of theory, research, and clinical practice. New York: Guilford; 2002. p. 135.

6. Fonseca H, Gaspar de Matos M. Perception of overweight and obesity among Portuguese adolescents: an overview of associated factors. Eur J Public Health. 2005;15:323-8.

7. Mooney $\mathrm{E}$, Farley $\mathrm{H}$, Strugnell $\mathrm{C}$. A qualitative investigation into the opinions of adolescent females regarding their body image concerns and dieting practices in the Republic of Ireland (ROI). Appetite. 2009;52:485-91.

8. Mäkinen $M$, Puukko-Viertomies LR, Lindberg N, Siimes MA, Aalberg V. Body dissatisfaction and body mass in girls and boys transitioning from early to mid-adolescence: additional role of self-esteem and eating habits. BMC Psychiatry. 2012;12:35.

9. Bucchianeri MM, Arikian AJ, Hannan PJ, Eisenberg ME, NeumarkSztainer D. Body dissatisfaction from adolescence to young adulthood: findings from a 10-year longitudinal study. Body Image. 2013;10:1-7.

10. Gitau TM, Micklesfield LK, Pettifor JM, Norris SA. Eating attitudes, body image satisfaction and self-esteem of South African Black and White male adolescents and their perception of female body silhouettes. J Child Adolesc Ment Health. 2014;26:193-205.

11. Alvarenga MS, Philippi ST, Lourenço BH, Sato PM, Scagliusi FB. Insatisfação com a imagem corporal em universitárias brasileiras. J Bras Psiquiatr. 2010;59:44-51.

12. Costa LCF, Vasconcelos FAG. Influência de fatores socioeconômicos, comportamentais e nutricionais na insatisfação com a imagem corporal de universitárias em Florianópolis, SC. Rev Bras Epidemiol. 2010;13:665-76.

13. Ingolfsdottir $G$, Asgeirsdottir BB, Gunnarsdottir $T$, Bjornsson AS. Changes in body image and dieting among 16-19-year-old Icelandic students from 2000 to 2010. Body Image. 2014;11:364-9.

14. Głogowska J, Milde K, Stupnicki R. Body image of tall and medium girls aged 13-17 years. Pediatr Endocrinol Diabetes Metab. 2011;17:92-5.

15. Sonneville KR, Calzo JP, Horton NJ, Haines J, Austin SB, Field $A E$. Body satisfaction, weight gain, and binge eating among overweight adolescent girls. Int J Obes (Lond). 2012;36:944-9.

16. McLaughlin EA, Belon KE, Smith JE, Erickson SJ. Mothers' and daughters' beliefs about factors affecting preadolescent girls' body satisfaction. Body Image. 2015;13:9-17.

17. Laus MF, Kakeshita IS, Costa TM, Ferreira ME, Fortes Lde S, Almeida SS. Body image in Brazil: recent advances in the state of knowledge and methodological issues. Rev Saude Publica 2014;48:331-46.

18. Smolak L. Body image development in childhood. In: Cash TF, Smolak L. Body image: a handbook of science, practice, and prevention. 2nd ed. New York: Guilford; 2011. p. 67-75.

19. Pope HG Jr, Gruber AJ, Mangweth B, Bureau B, deCol C, Jouvent $\mathrm{R}$, et al. Body image perception among men in three countries. Am J Psychiatry. 2000;157:1297-301.

20. Hay PJ, Mond J, Buttner P, Darby A. Eating disorder behaviors are increasing: findings from two sequential community surveys in South Australia. PLoS One. 2008;3:e1541.

21. Maximova K, McGrath J], Barnett T, O'Loughlin J, Paradis G, Lambert M. Do you see what I see? Weight status misperception and exposure to obesity among children and adolescents. Int J 
Obes (Lond). 2008;32:1008-15.

22. Fredrickson J, Kremer $P$, Swinburn B, de Silva A, McCabe M. Which measures of adiposity are related to Australian adolescent's perception of their weight? Acta Pædiatr. 2014;103:e317-24.

23. Habicht JP. Estandarización de métodos epidemiológicos cuantitativos sobre el terreno. Bol Oficina Sanit Panam. $1974 ; 76: 375-84$.

24. Ulijaszek SJ, Kerr DA. Antropometric measurement error and the assessment of nutritional status. Br J Nutr. 1999;82:165-77.

25. Kakeshita IS, Silva AIP, Zanatta DP, Almeida SS. Construção e fidedignidade teste-reteste de escalas de silhuetas brasileiras para adultos e crianças. Psic Teor e Pesq. 2009;25:263-70.

26. Lohman TG, Roche AFE, Martorell R. Anthropometric standardization reference manual. Illinois: Human Kinetics Books; 1991.

27. de Onis M, Onyango AW, Borghi E, Siyam A, Nishida C, Siekmann J. Development of a WHO growth reference for school-aged children and adolescents. Bull World Health Organ. 2007;85:660-7.

28. Lohman TG. Applicability of body composition techniques and constants for children and youths. In: Pandolf KB, editor. Exercise and sport sciences reviews. New York: Macmillan; 1986. p.25357.

29. Lohman TG. The use of skinfold to estimate body fatness on children and youth. JOPERD. 1987;58:98-102.

30. Taylor RW, Jones IE, Williams SM, Goulding A. Evaluation of waist circumference, waist-to-hip ratio, and the conicity index as screening tools for high trunk fat mass, as measured by dualenergy $X$ ray absorptiometry, in children aged 3-19 y. Am J Clin Nutr. 2000;72:490-5.

31. Araújo CL, Dumith SC, Menezes AM, Hallal PC. [Measured weight, self-perceived weight, and associated factors in adolescents]. Rev Panam Salud Publica. 2010;27:360-7.

32. Ursoniu S, Putnoky S, Vlaicu B. Body weight perception among high school students and its influence on weight management behaviors in normal weight students: a cross-sectional study. Wien Klin Wochenschr. 2011;123:327-33.

33. Cho JH, Han SN, Kim JH, Lee HM. Body image distortion in fifth and sixth grade students may lead to stress, depression, and undesirable dieting behavior. Nutr Res Pract. 2012;6:175-81.

34. Rivera-Soto WT, Rodríguez-Figueroa L. Childhood obesity among Puerto Rican children: discrepancies between child's and parent's perception of weight status. Int J Environ Res Public Health. 2012;9:1427-37.
35. Hussin DK, Mohammad IH, Al-Hamad HA, Makboul G, Elshazl M. Weight status and perceived body size image in overweight and obese children 8-12 years old. Alexandria J Med. 2011;47:365-71.

36. Castro MR, Ferreira VN, Chinelato RC, Ferreira ME. Body image in women undergone bariatric surgery: sociocultural interactions. Motricidade. 2013;9:82-95.

37. Singh AS, Mulder C, Twisk JW, van Mechelen W, Chinapaw MJ. Tracking of childhood overweight into adulthood: a systematic review of the literature. Obes Rev. 2008;9:474-88.

38. van Vliet JS, Kjölhede EA, Duchén K, Räsänen L, Nelson N. Waist circumference in relation to body perception reported by Finnish adolescent girls and their mothers. Acta Pædiatr. 2009;98:501-6.

39. World Health Organization (WHO). Obesity: preventing and managing the global epidemic. Geneva: WHO; 2000. WHO Technical Report Series.

40. Rosales Ricardo Y. [Anthropometry in the diagnosis of obese patients: a review]. Nutr Hosp. 2012;27:1803-9.

41. Smolak L. Body image development - girl children. In: Cash T. Encyclopedia of body image and human appearance. Virginia: Academia; 2012. p. 212.

42. Harring HA, Montgomer K, Hardin J. Perceptions of body weight, weight management strategies, and depressive symptoms among US college students. J Am Coll Health. 2010;59:43-50.

43. Liechty JM. Body image distortion and three types of weight loss behaviors among nonoverweight girls in the United States. J Adolesc Health. 2010;47:176-82.

44. Cattelino E, Bina M, Skanjeti AM, Calandri E. Anthropometric characteristics of primary school-aged children: accuracy of perception and differences by gender, age and BMI. Child Care Health Dev. 2014 Nov 17. [Epub ahead of print]

\section{Correspondence:}

Francisco de Assis Guedes de Vasconcelos

Departamento de Nutrição, Centro de Ciências da Saúde

Universidade Federal de Santa Catarina

Campus Reitor João David Ferreira Lima - Trindade

88040-900 - Florianópolis, SC - Brazil

E-mail: f.vasconcelos@ufsc.br 
The authors of the article entitled "Association between inaccurate estimation of body size and obesity in schoolchildren" (doi: http://dx.doi.org/10.1590/2237-6089-2015-0009), namely, Larissa da Cunha Feio Costa, Diego Augusto Santos Silva, Sebastião de Sousa Almeida, and Francisco de Assis Guedes de Vasconcelos, identified an error in the version published in Trends in Psychiatry and Psychotherapy, 2015, volume 37, issue 4, pages 220-226. On page 222, first column, third new paragraph, the text below:

"... classifies BMI as low for age (BMI < z score -2$)$; normal weight (BMI $\geq z$ score -2 and $<$ z score +1 ); overweight (BMI $\geq z$ score +1 and $<z$ score +2 ) and obesity (BMI $\geq z$ score +2 ). However, for the purposes of analysis, BMI was categorized as follows: not overweight/obese (BMI $<$ z score +1 ); overweight (BMI z score $\geq+1$ and $<z$ score +2 ); and obese (BMI z score $\geq+2$ )."

should read

"... classifies BMI as low for age (BMI < z score -2 ); normal weight (BMI $\geq z$ score -2 and $\leq \mathrm{z}$ score +1 ); overweight $($ BMI $>z$ score +1 and $\leq z$ score +2 ) and obesity (BMI $>$ z score +2$)$. However, for the purposes of analysis, BMI was categorized as follows: no overweight/obese (BMI $\leq$ z score +1 ); overweight (BMI z score $>+1$ and $\leq z$ score +2 ); and obese (BMI z score > +2)." 